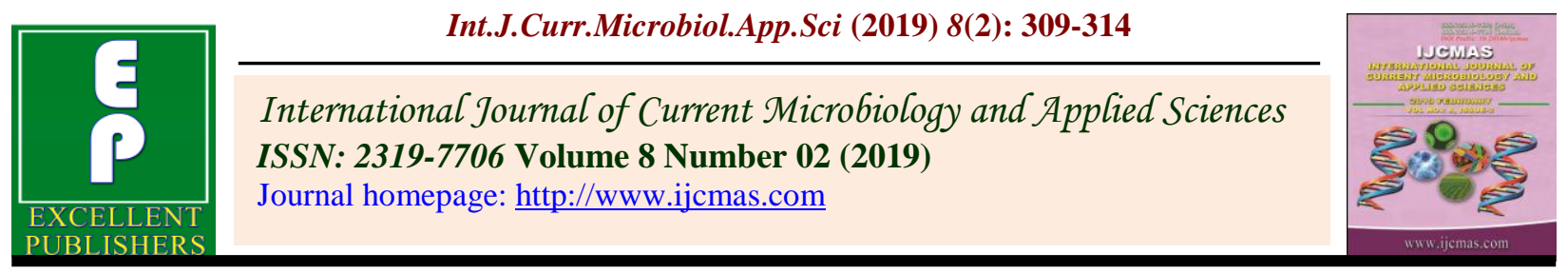

Original Research Article

https://doi.org/10.20546/ijcmas.2019.802.036

\title{
Aerobic Bacteriological Profile of Surgical Site Infection with Special Reference to MRSA at Hitech Medical College and Hospital, Bhubaneswar
}

\author{
Neha Patnaik, Bandana Mallick and Amruta Kar* \\ Department of Microbiology, Hitech Medical College and Hospital, Bhubaneswar, \\ Odisha, India \\ *Corresponding author
}

\begin{tabular}{|c|}
\hline Keywords \\
\hline $\begin{array}{l}\text { Surgical site } \\
\text { infection, MRSA, } \\
\text { Acinetobacter, } \\
\text { Antibiogram }\end{array}$ \\
\hline Article Info \\
\hline $\begin{array}{l}\text { Accepted: } \\
\text { 04 January } 2019 \\
\text { Available Online } \\
\text { 10 February } 2019\end{array}$ \\
\hline
\end{tabular}

A B S T R A C T

Surgical site infections are considered as the commonest nosocomial infections after urinary tract infections and are responsible for increasing morbidity, mortality and economic burden. Advances in infection control practices have not completely eradicated this problem because of emergence of multidrug resistant bacteria. Aim of the study is to determine the incidence of SSIs and the prevalence of aerobic bacterial pathogens with their. A prospective observational study of pus samples from post operative wound infections was conducted in various surgical departments of Hi-Tech Medical college \& Hospital from November 2016 to July 2018.203 pus samples were collected from clinically diagnosed SSIs. Standard microbiological techniques were used to isolate and identify the organism. Antibiogram was determined by Kirby-Bauer disc diffusion method. Out of 2367 patients, 203(8.5\%) were found to have SSIs, out of which 86(42.3\%), 75(36.9\%) and 42(20.6\%) were from Surgery, Orthopedics and Obstetrics \& Gynaecology respectively. The common organisms isolated were Staphylococcus aureus 105(51.8\%), Escherichia coli 39(19.2\%), Pseudomonas spp. 28(13.7\%), Acinetobacter spp 22(10.8\%) and Klebsiella spp. 9(4.5\%). Antibiogram profile of Gram positive isolate revealed maximum sensitivity to Vancomycin and Teicoplanin and Gram negative isolates exhibited highest sensitivity to Amikacin, Imipenem and Meropenem. In the present study $55(52.38 \%)$ isolates were MRSA. The incidence of multidrug resistance pathogens as a cause of SSI is rising. Rapid and accurate detection of these pathogens and study of their antibiogram is important for prevention of morbidity and mortality associated with SSI.

\section{Introduction}

Surgical site infections constitute a major public health problem worldwide and are second most frequently reported nosocomial infections $^{1}$. In 1992, Centre for Disease Control (CDC,US) revised its definition of 'wound infection' by creating the definition 'surgical site infection' (SSI). ${ }^{2}$ Based on National Nosocomial Infection Surveillance (NNIS) system reports, SSIs are the third most frequently reported nosocomial infections accounting for 14 to $16 \%$ of all nosocomial infections among hospitalized patients. Incidence of SSIs in India reported to vary from $3.6 \%$ to $22.5 \%{ }^{3}$ 
Availability of epidemiological data from antibiotic susceptibility pattern in various hospitals can help surgeon employ a logical approach towards surgical site infection control. Also resistance to antimicrobials has become a serious problem necessitating in depth study of SSI to prevent the future complications in operated cases ${ }^{4}$.

The risk of developing a surgical site infection depends on the balance between factors determining the number of bacteria contaminating the site and the factors determining the resistance of the site against infection $^{5}$. It can occur commonly occurs between the fifth and tenth days after surgery and can cause life threatening postoperative complication $^{6}$.

Staphylococcus aureus is frequently isolated from surgical site infections which may serve as nidus for the development of systemic infections. Strains of Methicillin Resistant Staphylococcus aureus (MRSA) have become established as the prevalent strains in hospitals. Increased frequency of MRSA in hospitalized patients and possibility of Vancomycin resistance requires permanent control of MRSA spread in the hospital. ${ }^{7}$

Hence, this study was conducted with an objective to identify the organisms causing SSIs with special reference to MRSA and evaluate the antibiotic resistance pattern among the most common bacteria which are associated with SSIs.

\section{Materials and Methods}

This Prospective observational study was carried out in the Department of Microbiology, in collaboration with various surgical departments of Hi-tech medical college and hospital for a period of 24 months (November 2016 to October 2018). In the present study, a total of 203 pus samples were collected from surgical site infections, out of 2367 operated cases in 2 years from Department of Surgery, Orthopedics and Obstetrics \& Gynecology

\section{Inclusion criteria}

Patients of all age groups except neonates

Presence of post-operative surgical site infections

\section{Exclusion criteria}

Infection occurring 30 days after operation if no implant is in place.

Infection on episiotomy wound.

Detailed clinical history of the patient was taken with special reference to existing chronic disease, length of preoperative hospital stay, duration of operation and antimicrobial prophylaxis. Wound swabs (2) or pus from wounds were processed. Gram staining was done from one swab and findings were recorded. Another swab was used for culture on 5\% sheep blood agar and MacConkey agar. Inoculated plates were incubated at $37^{\circ} \mathrm{C}$. After overnight incubation growth was identified by standard bacteriological techniques including colony morphology, Gram staining from colony and biochemical properties were recorded ${ }^{8}$. Antibiotic susceptibility testing was done by Kirby-Bauer standard disc diffusion method on Muller-Hinton agar according to CLSI guidelines. The isolated Staphylococcus aureus strains were tested for MRSA by using cefoxitin disc.

\section{Results and Discussion}

The total number of operated cases in two years were 2367 out of which 720 (30.4\%) were from Surgery department, 947 (40\%) were from Orthopedics department and $700(29.6 \%)$ were from Obstetrics \& 
Gynaecology Department. Out of 203 SSIs, $86(42.3 \%)$ were from Surgery department, 75 (37\%) were from Orthopedics and 42 (20.7\%) were from Obstetrics and Gynaecology department. Overall incidence of SSI in our study was $8.5 \%$. The present study had 112 $(55.1 \%)$ male patients and 91(44.9\%) female patients suffering from SSI. Surgical site infections (SSIs) in Surgery department and
Orthopedics were commonly seen in patient age group 41-60yrs (39.5\% and 33.3\% respectively). More number of patients with SSIs were seen in the age group 21-40yrs $(47.6 \%)$ in Obstetrics \& Gynecology department. From total 203 SSIs, 101(49.7\%) were alone from emergency surgeries (Table 1 and 2).

Table.1 Distribution of isolated pathogens from different specialities

\begin{tabular}{|l|l|l|l|}
\hline SL. NO. & SPECIALITY & $\begin{array}{l}\text { TOTAL NO. OF } \\
\text { PATIENTS n=2367 } \\
(\mathbf{\%})\end{array}$ & $\begin{array}{l}\text { SAMPLES WITH } \\
\text { PATHOGENIC } \\
\text { GROWTH } \\
\mathbf{n = 2 0 3}\end{array}$ \\
\hline 1 & SURGERY & $720(30.4)$ & $86(42.3)$ \\
\hline 2 & ORTHOPEDICS & $947(40)$ & $75(37)$ \\
\hline 3 & OBS \& GYN & $700(29.6)$ & $42(20.7)$ \\
\hline
\end{tabular}

Table.2 Distribution of different pathogens from various departments

\begin{tabular}{|l|l|c|}
\hline SL.NO. & PATHOGEN ISOLATED & $\mathbf{n = 2 0 3 ( \% )}$ \\
\hline 1 & Staphylococcus aureus & $105(51.8)$ \\
\hline 2 & Escherichia coli & $39(19.2)$ \\
\hline 3 & Pseudomonas spp. & $28(13.7)$ \\
\hline 4 & ACINETOBACTER spp. & $22(10.8)$ \\
\hline 5 & Klebsiella spp. & $9(4.5)$ \\
\hline & MRSA & $55(52.38)$ \\
\hline
\end{tabular}

Table.3 Antibiotic sensitivity pattern of gram positive isolates

\begin{tabular}{|l|l|l|l|}
\hline SL.NO & ANTIBIOTIC & $\begin{array}{l}\text { MRSA } \\
\mathbf{n = 5 5 ( \% )}\end{array}$ & $\begin{array}{l}\text { MSSA } \\
\mathbf{n = 5 0}(\%)\end{array}$ \\
\hline 1 & Oxacillin & 0 & 50 \\
\hline 2 & Ampicillin-sulbactam & $11(20)$ & $30(30.6)$ \\
\hline 3 & Vancomycin & $55(100)$ & $50(100)$ \\
\hline 4 & Linezolid & $55(100)$ & $50(100)$ \\
\hline 5 & Erythromycin & $21(38.1)$ & $23(46)$ \\
\hline 6 & Clindamycin & $32(58.1)$ & $34(68)$ \\
\hline 7 & Azithromycin & $20(36.3)$ & $17(34)$ \\
\hline 8 & Cotrimoxazole & $23(43.4)$ & $20(40)$ \\
\hline 9 & Ciprofloxacin & $17(30.9)$ & $22(44)$ \\
\hline 10 & Ofloxacin & $16(29.1)$ & $21(42)$ \\
\hline 11 & Tetracycline & $43(78.1)$ & $44(88)$ \\
\hline
\end{tabular}


Table.4 Antibiotic sensitivity pattern of Gram negative isolates

\begin{tabular}{|l|l|l|l|l|l|}
\hline $\begin{array}{l}\text { SL. } \\
\text { NO }\end{array}$ & Antibiotic & $\begin{array}{l}\text { Escherichia coli } \\
\mathbf{n = 3 9}(\mathbf{\%})\end{array}$ & $\begin{array}{l}\text { Klebsiella } \\
\mathbf{S P P} . \\
\mathbf{n = 9 ( \% )}\end{array}$ & $\begin{array}{l}\text { Pseudomonas } \\
\mathbf{s p p .} \\
\mathbf{n = 2 8}(\boldsymbol{\%})\end{array}$ & $\begin{array}{l}\text { Acinetobacter spp. } \\
\mathbf{n = 2 2}(\mathbf{\%})\end{array}$ \\
\hline 1 & Amikacin & $20(51.2)$ & $4(44.4)$ & $11(39.3)$ & $7(31.8)$ \\
\hline 2 & Gentamycin & $18(46.1)$ & $2(22.2)$ & $7(25)$ & $5(22.7)$ \\
\hline 3 & Tobramycin & $17(43.5)$ & $2(22.2)$ & $4(14.28)$ & $6(27.27)$ \\
\hline 4 & $\begin{array}{l}\text { Ampicillin- } \\
\text { sulbactam }\end{array}$ & $14(35.9)$ & $2(22.2)$ & NA & $6(27.27)$ \\
\hline 5 & $\begin{array}{l}\text { Piperacillin- } \\
\text { tazobactam }\end{array}$ & $15(38.4)$ & $3(33.3)$ & $5(17.8)$ & $4(18.18)$ \\
\hline 6 & Cefotaxime & $7(17.9)$ & 0 & NA & 0 \\
\hline 7 & Ceftazidime & $9(23.1)$ & $2(22.2)$ & $4(14.28)$ & 0 \\
\hline 8 & Ceftriaxone & $12(30.7)$ & $1(11.1)$ & NA & 0 \\
\hline 9 & Cefaperazone & $7(17.9)$ & $1(11.1)$ & $10(35.7)$ & $4(18.18)$ \\
\hline 10 & Cefepime & NA & NA & $15(53.6)$ & NA \\
\hline 11 & Imipenem & $27(69.2)$ & $5(55.5)$ & $19(68.85)$ & $13(59.09)$ \\
\hline 12 & Meropenem & $27(69.2)$ & $5(55.5)$ & $16(57.14)$ & $12(54.54)$ \\
\hline 13 & Cotrimoxazole & $9(23.1)$ & $1(11.1)$ & $2(7.14)$ & 0 \\
\hline 14 & Ciprofloxacin & $7(17.9)$ & $1(11.1)$ & $7(25)$ & 1 \\
\hline 15 & Levofoxacin & $7(17.9)$ & 0 & NA & 4 \\
\hline 16 & Tigecycline & $33(84.6)$ & $6(66.6)$ & NA & NA \\
\hline 17 & Aztreonam & NA & NA & $9(32.14)$ & NA \\
\hline 18 & Polymixin B & NA & NA & $26(92.85)$ & NA \\
\hline
\end{tabular}

Most common pathogens isolated were Staphylococcus aureus (51.8\%) followed by Escherichia coli (19.2\%), Pseudomonas spp. (13.7\%), Acinetobacter spp. (10.8\%) and Klebsiella spp. (4.5\%). Out of total 105 Staphylococcus aureus, 55 (52.38\%) were MRSA. In our study the only Gram positive isolate, Staphylococcus aureus from Surgery, Orthopedics and Obstetrics \& Gynecology department showed maximum sensitivity to Vancomycin and Linezolid. Gram negative isolates were sensitive to Tigecycline, Imipenem and Meropenem whereas maximum resistance was seen towards Cephalosporins. Nonfermenters showed maximum sensitivity towards Polymixin B. Despite the advances in surgical techniques and better understanding of the pathogenesis of wound infection, management of SSIs remains a significant concern for surgeons and physicians in a health care facility. Patients with SSIs face additional exposure to microbial populations circulating in a hospital setup which is always charged with microbial pathogens. The unrestrained and rapidly spreading resistance to the available array of antimicrobials further contributes to the existing problem.

Our study reported maximum isolation of Staphylococcus aureus (51.8\%) from SSIs followed by Escherichia coli (19.2\%), Pseudomonas spp. (13.7\%), Acinetobacter spp. (10.8\%) and Klebsiella spp. (4.5\%). Out of total 105 Staphylococcus aureus, 55(52.3\%) were MRSA. Prevalence of MRSA was $48.78 \%$ in study done by Khyati Jain et al., (2014, Indore) ${ }^{9}$ that was comparable to 
our study. Similar findings were observed by study of Ananthi et al., (2017, Chennai) ${ }^{10}$ and Vikrant Negi et al., (2015) ${ }^{1}$ that had Staphylococcus aureus (50.4\%) as the predominant organism.

In our study the only Gram positive isolate, Staphylococcus aureus (both MRSA strains and MSSA strains) showed maximum sensitivity to Vancomycin and Linezolid which correlates to study done by Shreeram et al., (2016, Jaipur) ${ }^{11}$. Gram negative isolates showed maximum sensitivity to Imipenem, Meropenem followed by Tigecycline which were comparable to study done by Amrutham et al., (2017, Telangana) ${ }^{12}$. Non-fermenters showed maximum resistance to Cephalosporins. Pseudomonas spp. showed highest sensitivity to Polymixin B followed by Imipenem and Meropenem. Acinetobacter spp. showed highest sensitivity to imipenem and meropenem followed by piperacillintazobactam and tobramycin.

Methicillin resistant Staphylococcus aureus (MRSA) have become increasingly prevalent worldwide. Due to an increasing number of infections caused by MRSA strains, which are now most often multiresistant, therapy has become problematic. MRSA spreads by direct physical contact or transmitted indirectly by contact with towels, clothes etc. surgical patients are at risk of infection if they are colonized with MRSA or if MRSA is inoculated into their surgical wound by contaminated hands or instruments including dressing scissors. The knowledge of the causative agents of wound infection has proved to be helpful in selection of antimicrobial therapy and on infection control measures in the hospital.

The prevention of SSIs is essential as a major clinical, political and therapeutic challenge. Infection control measures should be opt such as the active surveillance of SSIs, implementation of infection control checklist, its compliance and training of healthcare workers, MRSA screening, adherence to pre and peri-operative antibiotic prophylaxis, maintaining intra-operative temperature and blood glucose level are essential in order to prevent SSIs. Guidelines and protocols for basic infection control practices such as hand washing and insertion of intravascular cannulas and catheters should be widely available and adhered to it (Table 3 and 4).

To conclude, early detection and intervention of cases of surgical site infection (SSI) is a prerequisite in surgical patients to decrease the incidence of morbidity, mortality and wastage of health care resources although they cannot be completely eliminated, a reduction in the infection rate to a minimal level could have significant benefits. Antimicrobial therapy should be designed in such a way that it will deliver an adequate drug concentration to the site of infection. Hence, necessary steps should be implemented to follow the national antibiotic policy as per the guidelines. General awareness regarding transmission of MRSA infection should be created among all the health care personnel. Although complete eradication of wound infections is not possible however by taking preventive measures, adopting prompt clean surgical procedures starting from strict adherence to proper hand washing technique, instituting sensitivity based antibiotic treatments and proper care of surgical wounds, the incidence of wound infection can be reduced.

\section{References}

1. Negi V, Pal Shekhar, Juyal D, Sharma MK. Bacteriological profile of surgical site infections and their antibiogram: A study from resource constrained rural setting of Uttarakhand State, India. Journal of Clinical and Diagnostic 
Research. 2015 Oct. Vol-9(10): DC 17DC20.

2. Horan TC, Gaynes RP, Martene WJ, Jarvi WR, Emori TG. CDC definition of nosocomial surgical, a modification of CDC definition of surgical site infections. AM J Infect Control. 1992; 20: 271-274.

3. Emori TG, Gaynes RP. An overview of nosocomial infections, including the role of medical laboratory. Clin Microbiol Rev. 1993; 6(4): 428-42.

4. Anvikar AR, Deshmukh AB. A one year prospective study of 3820 surgical wounds. I J M M.1999; 17(3) 129-32.

5. Abid Mahmood. Bacteriology of surgical site infections and Antibiotic susceptibility pattern of the isolates at a Tertiary Care Hospital in Karachi. Journal of Pakistan Medical Association 200; 50(8): 256-9.

6. Surgical site infection. Prevention and treatment of surgical site infection. National Institute of Health and Clinical Excellence. Clinical Guideline CG 74 2008 Available at www.nice.org.uk/nicemedia/live/11743/ 42378/42378.pdf.

7. Krishna S., Divya P, Shafiyabi S. Postoperative surgical wound infections with special reference to methicillin resistant Staphylococcus aureus: an experience from vims hospital, Ballari, India. Journal of Bioscience and Technology. Vol. 6(3), 2015, 697-702.

8. Mackie \& McCartney. Practical Medical Microbiology.14th Edition:

9. Khyati Jain, Chavan NS, Jain SM. Bacteriological profile of post-operative wound infection along with special reference to MRSA in central India, Indore. International Journal of Integrative Medical Sciences, 2014: Vol 1(1): 9-13.

10. B. Ananthi, M. Ramakumar. Aerobic Bacteriological Profile and Antimicrobial Susceptibility Pattern in Postoperative Wound Infections at a Tertiary Care Hospital. International Journal of Medical Science and Clinical Inventions 2017. Vol 4(2): 2702-2706.

11. Shreeram G, Devesh S. Bacteriological profile and antibiogram of aerobic wound infection isolates in a tertiary care hospital. International Journal of Medical Science and Education. 2016 Apr-Jun; Vol 3(3): 251-56.

12. Rajanikanth A, M M Reddy. A prospective study of surgical site infections and related risk fctors in a teaching hospital. Int Surg J. 2017 Jan; 4(1): 237-241.

\section{How to cite this article:}

Neha Patnaik, Bandana Mallick and Amruta Kar. 2019. Aerobic Bacteriological Profile of Surgical Site Infection with Special Reference to MRSA at Hitech Medical College and Hospital, Bhubaneswar. Int.J.Curr.Microbiol.App.Sci. 8(02): 309-314. doi: https://doi.org/10.20546/ijcmas.2019.802.036 